\title{
Mathematics Education in a Multilingual and Multicultural Environment
}

\author{
Anjum Halai and Richard Barwell
}

\section{Introduction}

For this topic study group, 35 papers were accepted from a range of different cultural, linguistic and country contexts. The papers were discussed under specific thematic questions. These themes provide an organizing framework for this report that draws its content from the papers and the discussion in the TSG 30 sessions. The submissions illustrated the rich diversity in the kinds of issues that arise in mathematics education in multilingual and multicultural environments. These include challenges for teaching, learning, curriculum, pedagogy, teacher education and use of technology in and for multilingual and multicultural settings. Issues were at the level of policy (e.g. language of instruction) and at the level of classrooms (e.g. teaching methods, curriculum) and teacher education (e.g. models of preservice and teacher professional development). Diversity was also seen in terms of the geographical spread of the contexts from where papers were presented. The diversity of contexts reflects technologically advanced countries with increasingly large immigrant populations (e.g. Australia, Canada, Germany, Sweden, USA, UK), postcolonial countries with concomitant colonial languages as the medium of instruction (e.g. Ghana, Pakistan, Malaysia, South Africa, Tanzania) and countries with varied indigenous and official languages (e.g. China, India, Indonesia, Mexico,

Organizers Co-chairs: Anjum Halai (Pakistan), Clement Dlamini (Swaziland); Team Members: Richard Barwell (Canada), Nancy Chitera (Malawi), Dong Joong Kim (Korea); Liasion IPCMember: Frederick Leung (Hong Kong).

\author{
A. Halai $(\square)$ \\ Aga Khan University, Dar es Salaam, Tanzania \\ e-mail: anjum.halai@aku.edu \\ R. Barwell \\ Univeristy of Ottawa, Ottawa, Canada \\ e-mail: richard.barwell@uottawa.ca \\ (C) The Author(s) 2015
}

S.J. Cho (ed.), The Proceedings of the 12th International Congress

on Mathematical Education, DOI 10.1007/978-3-319-12688-3_55 
New Zealand). The overwhelming prevalence of issues related to quality of mathematics education in multilingual and multilingual contexts illustrates its significance.

\section{Theme One: What Is Distinctive About Learning and Teaching of Mathematics in Multicultural and Multilingual Settings?}

Presenters and participants identified several teaching strategies and distinctive elements of multilingual classrooms, highlighting potential for improving learners' mathematical skills. These included the use of group work, judicious questioning, implementation of second language teaching techniques in mathematics classrooms, promoting a positive climate in the classroom, enabling "translanguaging" i.e. to switch between the linguistic resources and cultures that learners have at their disposal (e.g. Farasani's work with British Iranian learners), and "exploratory talk" (e.g. the work of Webb and Webb in South Africa) as a vehicle to promote dialogue to enhance learners' reasoning skills in mathematics. An enduring concern for mathematics learning was students' lack of competence in the language of instruction. It was also noted that the discussion of papers in this theme emphasized issues arising specifically from multilingualism, as compared to multiculturalism.

\section{Theme Two: What Is the Experience of Education Systems that Have Changed the Medium of Instruction in Mathematics?}

Experiences were shared of learners and teachers from different country contexts where the medium of instruction was changed or different from the first language of the learners (e.g. Kasmer's and Kajoro's work in Tanzania) and multilingual classrooms with immigrant learners from several different first language backgrounds (e.g. Meyer's work with immigrant learners in Germany). For learners in multilingual postcolonial classrooms, presenters discussed several linguistically and culturally responsive teaching strategies such as the use of pictorial and other representations of mathematical ideas, situating the mathematics tasks in a familiar context, and code switching to facilitate learning. However, it was noted that there were tensions in classroom dynamics where a position of power and prestige was given to the language of instruction while learners' first language was not seen as a language of choice (e.g. Ampah-Mensah's work in Ghana).

In the case of classrooms where learners, often from immigrants communities, came from multiple language backgrounds not shared by the teacher and often not by other learners, it was concluded that an official language of the classroom was 
necessary to enable communication in the whole class. However, this necessity need not preclude strategies such as small group work where learners could use their home languages. Empowering the learners to take responsibility for their learning in small groups, and looking at the outcomes of the group work, could be strategies that teachers could employ in such multilingual settings. It was agreed in the discussion that the range of strategies and methods being employed by teachers and learners in the multilingual classrooms needed to be evaluated for their efficiency and effectiveness.

\section{Theme Three: How Can Mathematics Teaching Respond to the Oppression of Cultural and Linguistic Minorities?}

Studies in this theme reported different models (e.g. the "bi-cultural curriculum model" in New Zealand presented by Jorgensen), and teaching methods (e.g. Matematika GASING Method in Indonesia by Surya and Moss) for responding to the needs of learners from cultural and linguistic minorities. While there were subtle differences in the orientation and motives of these methods and models, they were mainly premised on the view that all children can learn mathematics provided they have opportunity to do so, and that the opportunity should be to access culturally and linguistically relevant mathematics teaching and learning. It was also recognized by these proponents that language, culture and mathematics pedagogy are integrally bound in a complex relationship. The models and methods proposed certain key elements of teaching that could be employed in mathematics classrooms for learners from culturally and linguistically marginalized or minority groups. For example, exposing learners to multicultural visual representation and conceptual tools before abstract mathematics notation; ensuring "respect" for learners in multiethnic classrooms by creating ample space to listen to them and guide their thinking (e.g. Averill and Clark's work in New Zealand); and taking a "bi-cultural focus" in the curriculum that legitimizes the culture of the school and of the community. However, in the discussion an issue was raised that culture was a broad and potentially nebulous term and needed further clarity in terms of its application to mathematics education.

\section{Theme Four: How Does/Should Teacher Education Take Account of Cultural and Linguistic Diversity?}

In this strand, it was pointed out that pre-service teacher education must take account of multilingual classrooms and recognized that a vast majority of learners learn mathematics in a second or third language. Exemplars of teacher education programmes included the presentation by Prediger and team, on the notion of an 
inter-disciplinary teacher education course proposing that mathematics teachers need to have didactic and linguistic knowledge and cultural sensitivity to understand the challenges that might be faced by the learners from diverse settings. Likewise interventions in teacher education provided a range of strategies and techniques that could be employed with teachers and students. These included, dialogic strategies and "exploratory talk" to promote mathematical reasoning among students, extended wait time for second language learners of mathematics, need for clarity and avoidance of slang in use of language in multilingual classrooms, utilizing learners' fluency in their main language as well as to garner the aid of a more able peer. The few studies that harnessed the potential of technology to enhance the cultural understanding and experience of learning mathematics in a second or third language included the use of video-conferencing, social media and Skype as a medium to provide experience of teaching in a multilingual setting and enhance cultural understanding (e.g. the work of Moss and Boutwell with preservice teachers in USA, Singapore and Haiti). A conclusion was that technology provided a relatively easy opportunity for teaching mathematics within a multicultural and multilingual environment. With creativity, connections, and technology, pre-service mathematics teachers could learn about mathematics, teaching, and culture in other countries without leaving their own.

\section{Theme Five: How Do Curricula and Policy Take Account (or not) of Cultural and Linguistic Diversity?}

In this theme the focus was more on curricular processes (not necessarily curricular content) embedded in instructional sequence, pedagogy and teaching strategies for improved teaching and learning in diverse contexts. For example a teaching sequence was presented by Xaab Vasquez, based on the philosophy of "Wejën Kajën" in Oaxaca in Mexico, which encourages reflection on the prevailing education processes and the need to make explicit that learners are not isolated but are situated in a wider social and cultural context. Cooperative learning strategies were presented as an approach to create space for marginalized learners to improve achievement in mathematics. Similarly, presentations proposed differentiated instruction sensitive to the needs of minority students and "equitable strategies" that encourage collaborative knowledge production, student authority and ownership of knowledge, and mutual respect (e.g. the work of Manjula and Erchick in USA). Such strategies should be guided by the principle of reducing discontinuities between the lives of students by drawing on their cultural heritage to create an egalitarian context for supporting the learning of all students (e.g. the work of Ryoon Jin Song and team in South Korea). Use of mathematics investigations, films, print literature and internet websites were also seen as ways to accommodate cultural diversity in the classroom. The case was also presented of the International Baccalaureate Diploma Program, IB, which operates in three languages (English, 
French and Spanish). It was pointed out that the IB curriculum is integrally concerned with the international dimensions of mathematics and the multiplicity of its cultural and historical perspectives, which in turn helps to discover new perspectives and horizons in international mathematical education.

\section{Theme Six: What Theoretical Perspectives on Cultural and Linguistic Diversity Are Most Helpful in Investigating The Teaching and Learning of Mathematics?}

Several theoretical frameworks and conceptual models were presented in this theme to provide tools for understanding and analyses of issues related to teaching and learning of mathematics in contexts of cultural and linguistic diversity. For example these included the presentation by Essien and team on an extension of Wenger's work on "communities of practice" for application to pre-service teacher education for multilingual mathematics classrooms. Likewise an integrated model was presented that integrates three hitherto disparate registers: those of code switching, transitions between informal and academic (mathematical) forms of language within a given language, and transitions between different mathematical representations. However, it was pointed out that further research was required to establish the efficacy of this model. Sevensson's presentation raised issues related to research methodology in ensuring that "students' voices" are heard. Barwell and team presented work that extended Bakhtin's (1981) theory of language and claimed that the theory provides a framework for looking at the tensions in mathematics classrooms in diverse language contexts but go on to state that more research is needed in this area.

\section{Concluding Remarks}

Certain key overarching questions or concerns were raised for further deliberation about the quality of mathematics education in diverse linguistic and cultural settings. These include: "Where is the mathematics in talking about the methodological, political and equity issues in multilingual and multicultural classrooms?" It was reiterated that meetings like ICME are primarily about mathematics education and therefore mathematics should be in the foreground. A concern was that metaconcepts like "culture" and "language" were employed in the discussion as if there existed a shared understanding of these concepts. However, there needs to be discussion and debate to problematize these notions and clarify their usage in mathematics education. Also it was noted that even though the title of the TSG 30 and the themes included "multilingualism" and "multiculturalism" the papers and discussion tended to focus on issues related to multilingualism. 
Acknowledgments The contribution of the committee members especially Clement Dlamini, authors and participants in TSG 30 are sincerely acknowledged.

Open Access This chapter is distributed under the terms of the Creative Commons Attribution Noncommercial License, which permits any noncommercial use, distribution, and reproduction in any medium, provided the original author(s) and source are credited.

\section{Reference}

Bakhtin, M. M. (1981). The Dialogic Imagination: Four Essays. (Ed., M. Holquist; Trans, C. Emerson and M. Holquist). Austin, TX: University of Texas Press. 